\title{
SYNTHESIS, CHARACTERISATION AND ANTIBACTERIAL ACTIVITY OF COPOLYMER (N-VINYLPYRROLIDONE - MALEIC ANHYDRIDE) WITH N- DIETHYLETHANOLAMINE
}

\author{
Hemalatha $P^{1}$, M K Veeraiah ${ }^{2}$, Prasannakumar $S^{3}$, Anasuya K $V^{4}$ \\ ${ }^{1}$ Lecturer, ${ }^{2}$ Prof and Head, Dept of Chemistry,' Sri Siddhartha Institute of Technology, Tumkur, Karnataka, India \\ ${ }^{3}$ Head R\&D, Clov Chem. India Private Limited, Harohalli, Bangalore. Karnataka, India. \\ ${ }^{4}$ Asst.Prof. Department of Chemistry, Govt First Grade College and PG Centre, Davanagere, Karnataka, India
}

\begin{abstract}
A copolymer of $N$-vinylpyrrolidone (NVP) with maleic anhydride (MA) is synthesized by radical copolymerization with 2,2-Azobisisobutyronitrile $(A I B N)$ as initiator at $65^{\circ} \mathrm{C}$ in dioxane solution, under nitrogen atmosphere. The copolymer obtained is characterized by FTIR and NMR. The copolymer is made to interact with N,N-Diethylaminoethanol (DEAE) in different ratios. The susceptibility of some Gram - negative bacteria like Klebsiella aerogenes NCIM-2098, Escherichia coli NCIM-5051, Pseudomonasaeruginosa NCIM2242, Pseudomonas desmolyticum NCIM-2028 and a Gram positive bacteria Staphylococcus aureus NCIM-5022, to the copolymer and its compound with N,N-Diethylaminoethanol of different compositions in microbiological medium is studied by Agar well diffusion method. The resulting polymeric antibacterial material is useful in a number of medicines and food industry.
\end{abstract}

Keywords: $N$-vinylpyrrolidone, Maleic anhydride, Copolymerization, N, N-diethylaminoethanol, FTIR, NMR, Antibacterial activity.

\section{INTRODUCTION}

Copolymers with reactive or functional monomers are steadily gaining importance. Many copolymers with reactive functional groups are now being synthesized, tested and used not only for their macromolecular properties, but also for the properties of functional groups [1]. These functional groups provide an approach to a subsequent modification of the polymer for the specific end applications [2]. Nowadays, a strong demand prevails for "functional polymer" with very specific properties. Functional groups give a polymer structure a special character substantially different from the inherent properties of the basic polymer chain [3].

The antimicrobial property of the polymers plays an important role for many of its applications. Contamination by microorganisms is of great concern in several areas such as medical devices, health care products, water purification systems, hospital and dental equipments etc. One possible way to avoid microbial contamination is to develop the polymeric materials possessing antimicrobial properties [4-10]. Antimicrobial polymers are those, which are capable of killing pathogenic micro-organisms. These polymeric biocides can significantly reduce the loss of antimicrobial activity associated with volatization, photolytic decomposition, dissolution and permeation migration. Moreover, increased efficiency, selectivity and handling safety are additional benefits that are realized $[11,12]$.

Antimicrobial activity of some linear copolymers, containing quaternary ammonium and phosphonium salts has been reported by Kenawy et al. [12, 5, 10]. Patel et al found that homo and copolymers of N-vinylpyrrolidone (NVP) and 2,4dichlorophenyl methacrylate (2,4 DMA) were effective in inhibiting selective microorganisms [4]. It has been reported that polymers prepared using 2,4 - DMA showed strong inhibitory effect towards such tested microorganism as bacterial strains (S. Aurus, S. Citreus and E.Coli), molds and yeasts, while poly(VP) has been shown to have relatively lower antimicrobial activity. Gottenbos et al. reported that quaternary ammonium silane - coated silicone rubber showed antimicrobial properties against adhering bacteria, both Gram - positive and Gram - negative [13]. Ayhan Temiz et al. studied the antimicrobial behavior of Poly (Nvinylpyrrolidone - alt-Maleic anhydride) and it's Poly (ethyleneimine) macro complexes in aqueous solution and reported that Gram - positive bacteria affected by the complex but Gram - negative bacteria are not affected [14].

$\mathrm{N}$-vinylpyrrolidone is a good biocompatible monomer due to its hydrophilic nature and low toxicity [15-17]. The amide group of NVP has a high affinity for several small and large 
molecules that are known as good hydrogen-bond acceptors and has been copolymerized with a variety of monomers [1822]. Homo and copolymers of N-vinylpyrrolidone (VP) are of considerable academic and industrial interest due to their unique properties, allowing the use of these polymer systems in lithography as light sensitive thin coatings for printing plates, for the preparation of separating membranes for ultra filtration, biocompatible polymers with low toxicity and carriers of biologically active compounds, sorbents, coagulants and flocculants [23-27]. Copolymer of 2hydroxymethylmethacrylate (HEMA) and N-vinylpyrrolidone is used in pharmaceutical application, such as, cancer therapy [28]. Copolymer of NVP and n-butylmetharylate are used for blood purification therapies [29]. Fullerene (60) C complexed with Poly (N-vinylpyrrolidone) is used in antiviral activity [30].

The use of maleic anhydride (MA) copolymers in medicine or pharmacy was described as antitumor agents, [31-33] drug carriers, supporters for enzymes or protein modifiers [34-37]. Antitumor functional polymers were synthesized by reaction of poly (MA-co-VP) with hydroxyl and amino containing physiologically active compound [38-40]. By the intermolecular reactions of poly (MA-co-styrene) [43] and poly(MA-co-methyl methacrylate) [41] with 3,6 - diamino10-methylacridiniumchloride (acriflavine as an antiseptic agent) in DMF and poly[( $N$-isopropylacrylamide-co-maleic anhydride)- $g$-poly(ethylene oxide)] using triethylamine as catalyst [44], new derivatives of these copolymers with antimicrobial properties were also synthesized.

In the present work, a copolymer of NVP and MA is synthesized. It is characterized by FTIR, $\mathrm{H}^{1} \mathrm{NMR}$ and $\mathrm{C}^{13}$ NMR. The synthesized copolymer is hydrolyzed. The product formed is made to react with $\mathrm{N}$-diethylaminoethanol to form a complex in two different ratios. The complexes formed are tested for antibacterial activity.

\section{EXPERIMENTAL}

\subsection{Materials}

\subsubsection{Chemicals}

N-vinyl-2-pyrrolidone (NVP) (Sigma-Aldrich) was purified before use by distillation under moderate vacuum. Maleic anhydride (MA) (Lobachem) was purified before use by recrystallisation from anhydrous benzene solution and sublimation in vacuum. 2,2-Azobisisobutyronitrile (AIBN) was purified by successive crystallization from chloroformmethanol mixture. N,N-Diethylaminoethanol was purified by distillation. The solvents used as copolymerization medium, for precipitation and extraction were all of analytical grade.

\subsubsection{Microbial Strains}

Antibacterial activity was screened by Agar well diffusion method [45] against five bacterial Strains Gram-ve Klebsiella aerogenes NCIM-2098, Escherichia coli NCIM5051, Pseudomonas aeruginosa NCIM2242, Pseudomonas desmolyticum NCIM-2028 and a Gram +ve bacteria Staphylococcus aureus NCIM-5022.

\subsection{Copolymer Synthesis}

The copolymer of $\mathrm{N}$-vinylpyrrolidone with maleic anhydride was prepared by radical initiated copolymerization in 1,4dioxane at $65^{\circ} \mathrm{C}$ in the presence of AIBN as initiator in three necked round bottom flask under nitrogen atmosphere using equimolar monomer mixture. The reaction mixture was continuously stirred for 48 hours. Copolymer was isolated from the reaction mixture and purified from 1,4 - dioxane solution to diethylether (Figure -1). It was precipitated with acetone. The precipitate was washed well with acetone. The copolymer was then isolated by centrifugation and dried at $40^{\circ} \mathrm{C}$ under vacuum to constant weight.

The copolymer (M) prepared was made to react with $\mathrm{N}, \mathrm{N}$ diethylaminoethanol at $40^{\circ} \mathrm{C}$ in aqueous solution in different concentrations 1:1(M1), 1:2(M2). The copolymer (M), the copolymer complexes (M1, M2) were tested for antibacterial activity. 


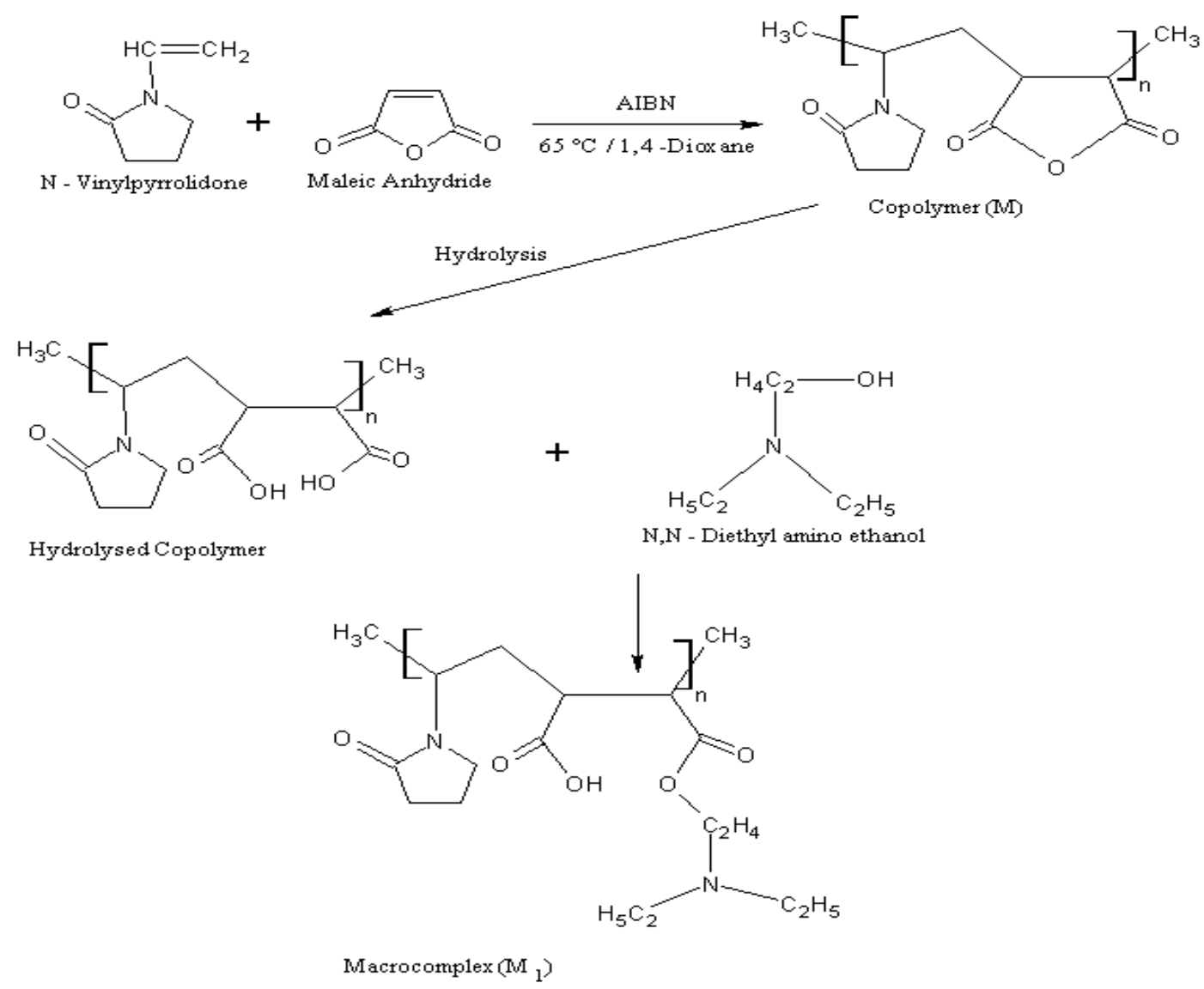

Fig 1: Reaction scheme of N-Vinylpyrrolidone and Maleic anhydride, hydrolyzed copolymer and poly(NVP-Co-MA) / DEEA macro complex

\subsection{Copolymer Characterization}

Copolymers were characterized by FTIR spectra using Shimadzu - 1800S spectrometer on $\mathrm{KBr}$ pellets in the range of $400-4000 \mathrm{~cm}^{-1}$. The $\mathrm{H}^{1}$-NMR and $\mathrm{C}^{13}$-NMR (Brucker AMX400 , at Indian Institute of Science, Bangalore) spectra of copolymer were recorded in methanol as solvent and tetramethylsilane (TMS) as an internal standard.

\subsection{Antimicrobial Activity Test}

Nutrient Agar Culture medium plates were prepared and swabbed using sterile L-shaped glass rod with $100 \mu \mathrm{l}$ of $24 \mathrm{~h}$ mature broth culture of individual bacterial strains. The wells were made by using sterile cork borer of $6 \mathrm{~mm}$ in each petriplate. Varied concentrations of given compound $(1000 \mu \mathrm{g} / \mathrm{well})$ were used to assess the activity of the compounds. The compound dispersed in sterile water acts as a negative control and the standard antibiotics Ciprofloxacin $(5 \mu \mathrm{g} / 50 \mu \mathrm{l})$ (Hi Media, Mumbai, India) acts as positive control were tested against the bacterial pathogens. Then the plates were incubated at $37{ }^{\circ} \mathrm{C}$ for $24-$ 36 hours. The zone inhibition was measured in millimeter for the every well and also the values were noted. Triplicates were maintained in every concentration and the average values were calculated for the ultimate antibacterial activity.

\section{RESULTS AND DISCUSSION}

\subsection{Characterization of Copolymer}

\subsubsection{Solubility Studies}

Solubility of the Copolymer was tested in various polar and non polar organic solvents. It was soluble in solvents like tetrahydrofuron, dimethylsulfoxide, dimethylformamide, dimethylacetamide, isopropylalcohol and methanol. Whereas, it was insoluble in ethylacetate, chloroform, 1,4-dioxane, chlorobenzene, toluene, n-hexane, n-heptane, cyclohexane, carbontetrachloride, diethyl ether and benzene.

\subsubsection{Fourier Transform Infrared (FTIR) Spectral} Studies

The structure of copolymer was confirmed by FTIR spectra as shown in Figure -2 . 


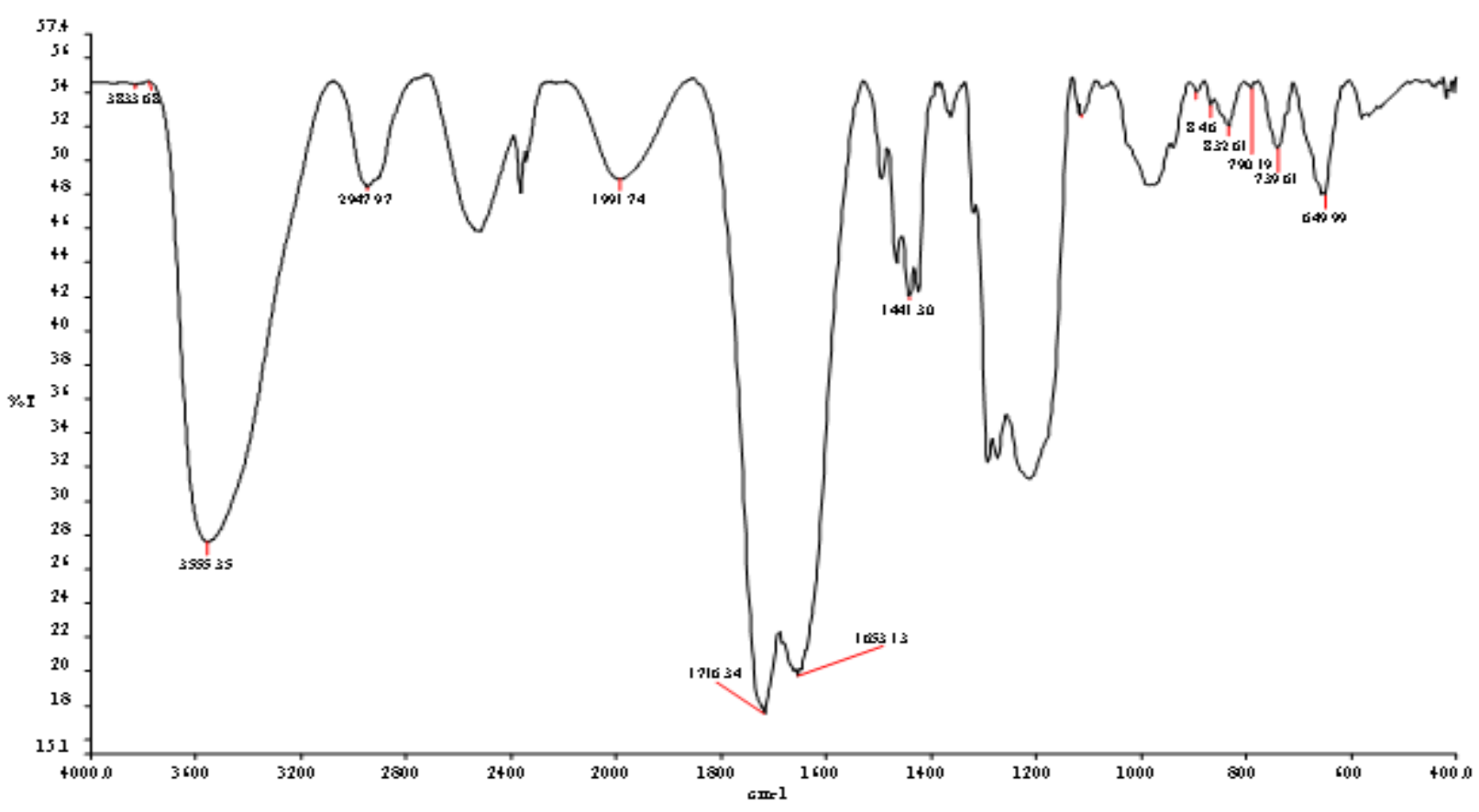

Fig 2: FTIR Spectra of prepared NVP - MA Copolymer

The structure of the copolymer is confirmed by FTIR spectra as shown in Fig-2. Only important peaks are assigned.

NVP $1653.13 \mathrm{~cm}^{-1}-\mathrm{C}=\mathrm{O}, \quad 1441.30 \mathrm{~cm}^{-1} \quad \mathrm{C}-\mathrm{N}-\mathrm{C}$,

MA $1991.74 \mathrm{~cm}^{-1}$ anhydride ring, $984.25 \mathrm{~cm}^{-1}$ cyclic anhydride,

Range 649.99 and $739.61 \mathrm{~cm}^{-1} \quad \mathrm{C}-(\mathrm{CH} 2)-\mathrm{C}$ of parent chain

\subsubsection{Nuclear Magnetic Resonance Spectroscopy $\left(\mathbf{H}^{1}\right.$} NMR):

The structure of copolymer is also confirmed by NMR spectral studies.

$\mathrm{H}^{1}-\mathrm{NMR}$ spectrum of copolymer is as shown in Fig -3 .
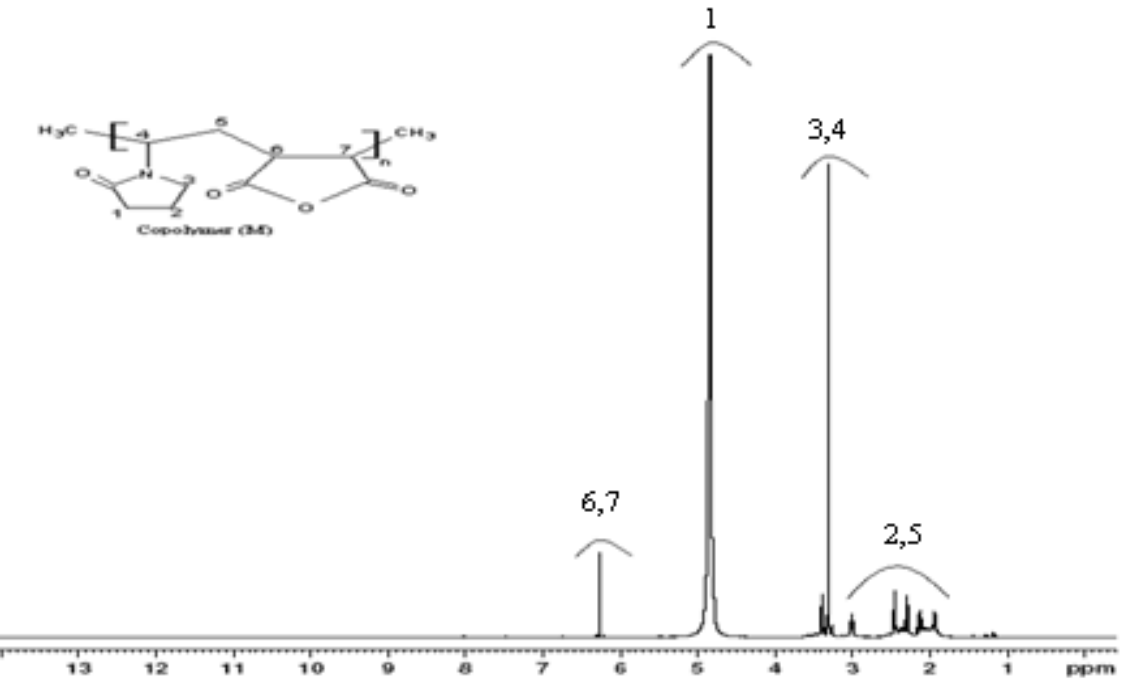

Fig 3: $\mathrm{H}^{1} \mathrm{NMR}$ Spectrum of Copolymer 
Ring methyl protons in NVP resonate at $4.9 \delta, 2.3 \delta$ and $3.2 \delta$. $\mathrm{CH}_{2}$ main chain back bone resonates at 3.5-2.5 $\delta$. Protons of maleic unhydride resonate at $6.2 \delta$.
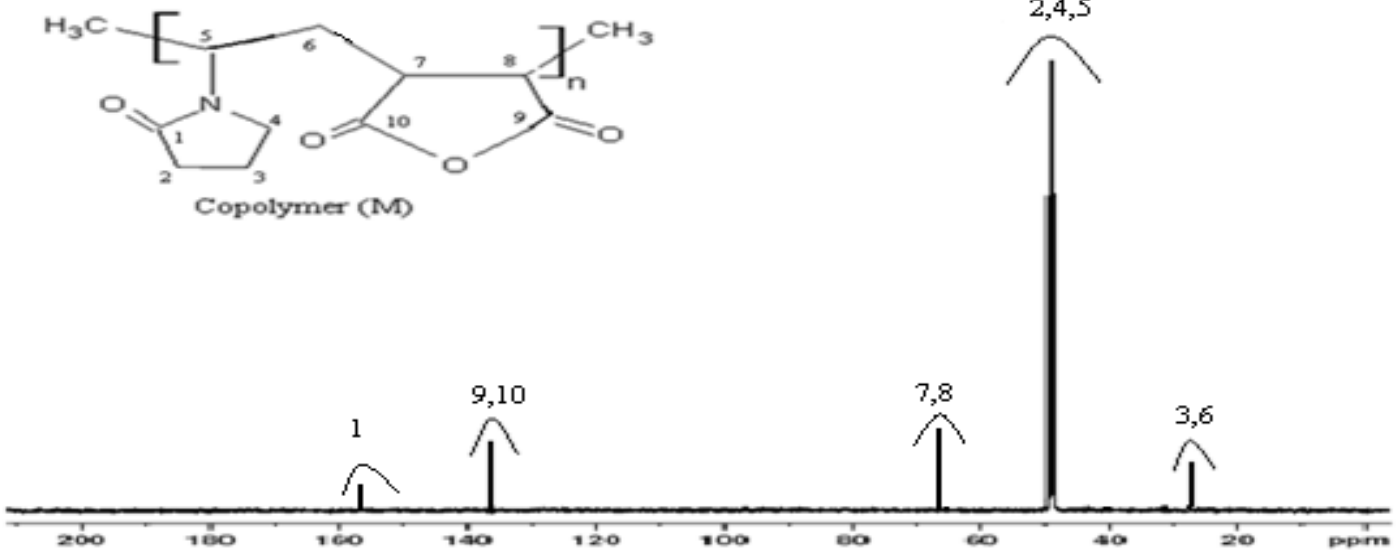

Figure 4: $C^{13}$ NMR Spectrum of Copolymer

\subsubsection{Nuclear Magnetic Resonance Spectroscopy $\left(C^{13}\right.$ NMR):}

The structure of copolymer was also confirmed by $\mathrm{C}^{13}-\mathrm{NMR}$ spectrum as shown in Fig -4 .
Ring methylene carbon of NVP resonates at $49.6 \delta, 43.59 \delta$ and $23.8 \delta$.

$\mathrm{C}=\mathrm{O}$ of $\mathrm{NVP}$ respnates at $157 \delta$,

$\mathrm{CH}_{2}$ Main chain back bone resonates at 48.2 and $21.2 \delta$.

Carbon atoms of maleic unhydride ring resonate at $136.13 \delta$

\subsection{Anti bacterial Properties of Copolymer and its}

\section{Compounds:}

The antibacterial properties of compounds were evaluated against four Gram-ve $K$. aerogenes, $E$. coli, $P$. aeruginosa, and $P$. desmolyticum and one Gram +ve S.aureus bacterial strains using agar well diffusion method. In agar well diffusion method the compounds showed significant antibacterial activity on all the four Gram-ve bacterial strains. $K$. aerogenes, E. coli, P.aeruginosa P. desmolyticum and then another bacteria Gram +ve S.aureus is inactive. The zone of inhibition with the concentration $1000 \mu \mathrm{g}$ per well is as shown in Fig.5. The data of zone of inhibition is depicted in Table 1.

Table-1: antibacterial activity of (M, M1, M2) on Pathogenic bacterial Strain

\begin{tabular}{|c|c|c|c|c|c|c|}
\hline Sl.no & Treatment & $\begin{array}{l}\text { Klebsiella } \\
\text { aerogenes }(B 1) \\
(\text { Mean } \pm \text { SE) }\end{array}$ & $\begin{array}{l}\text { Escherichia } \\
\text { coli }(B 2) \\
(\text { Mean } \pm \text { SE) }\end{array}$ & $\begin{array}{l}\text { Pseudomonas } \\
\text { aeruginosa }(B 3) \\
(\text { Mean } \pm \text { SE })\end{array}$ & $\begin{array}{l}\text { Staphyloccus } \\
\text { aureus (B4) } \\
\text { (Mean } \pm \text { SE) }\end{array}$ & $\begin{array}{l}\text { Pseudomonas } \\
\text { desmolyticum }(\text { B5) } \\
(\text { Mean } \pm \text { SE) }\end{array}$ \\
\hline I & $\begin{array}{l}\text { Standard } \\
(5 \mu \mathrm{g} / 50 \mu \mathrm{L})\end{array}$ & $12.67 \pm 0.33 * *$ & $13.67 \pm 0.33 * *$ & $13.67 \pm 0.33 * *$ & $13.67 \pm 0.33 * *$ & $14.67 \pm 0.33 * *$ \\
\hline II & $\begin{array}{l}\text { M } \\
(100 \mu \mathrm{g} / 100 \mu \mathrm{L})\end{array}$ & $1.33 \pm 0.33 * *$ & $1.33 \pm 0.33 * *$ & $2.67 \pm 0.33 * *$ & inactive & $2.67 \pm 0.33 * *$ \\
\hline III & $\begin{array}{l}\text { M1 } \\
(\mathbf{1 0 0 0} \mu \mathrm{g} / \mathbf{1 0 0} \mu \mathrm{L})\end{array}$ & $2.67 \pm 0.33 * *$ & $2.00 \pm 0.00$ & $3.67 \pm 0.33 * *$ & inactive & $3.00 \pm 0.00$ \\
\hline IV & $\begin{array}{l}\text { M2 } \\
(1000 \mu g / 100 \mu L)\end{array}$ & $1.67 \pm 0.33 * *$ & $2.67 \pm 0.33 * *$ & $5.67 \pm 0.33 * *$ & inactive & $1.00 \pm 0.00$ \\
\hline
\end{tabular}


Values are the mean \pm SE of clear zone in mm. Symbols represent statistical significance,

${ }^{*} P<0.05,{ }^{*} * P<0.01$ as compared with the control group.
aeruginosa(B3) and Pseudomonas desmolyticum(B5). The macro complex M1 and M2 are showing a better inhibition towards Pseudomonas aeruginosa(B3). Among all the compounds M2 is showing a very good antibacterial property.

From this table, it is evident that the Copolymer (NVP - MA)

is showing a better inhibition for the bacteria Pseudomonas
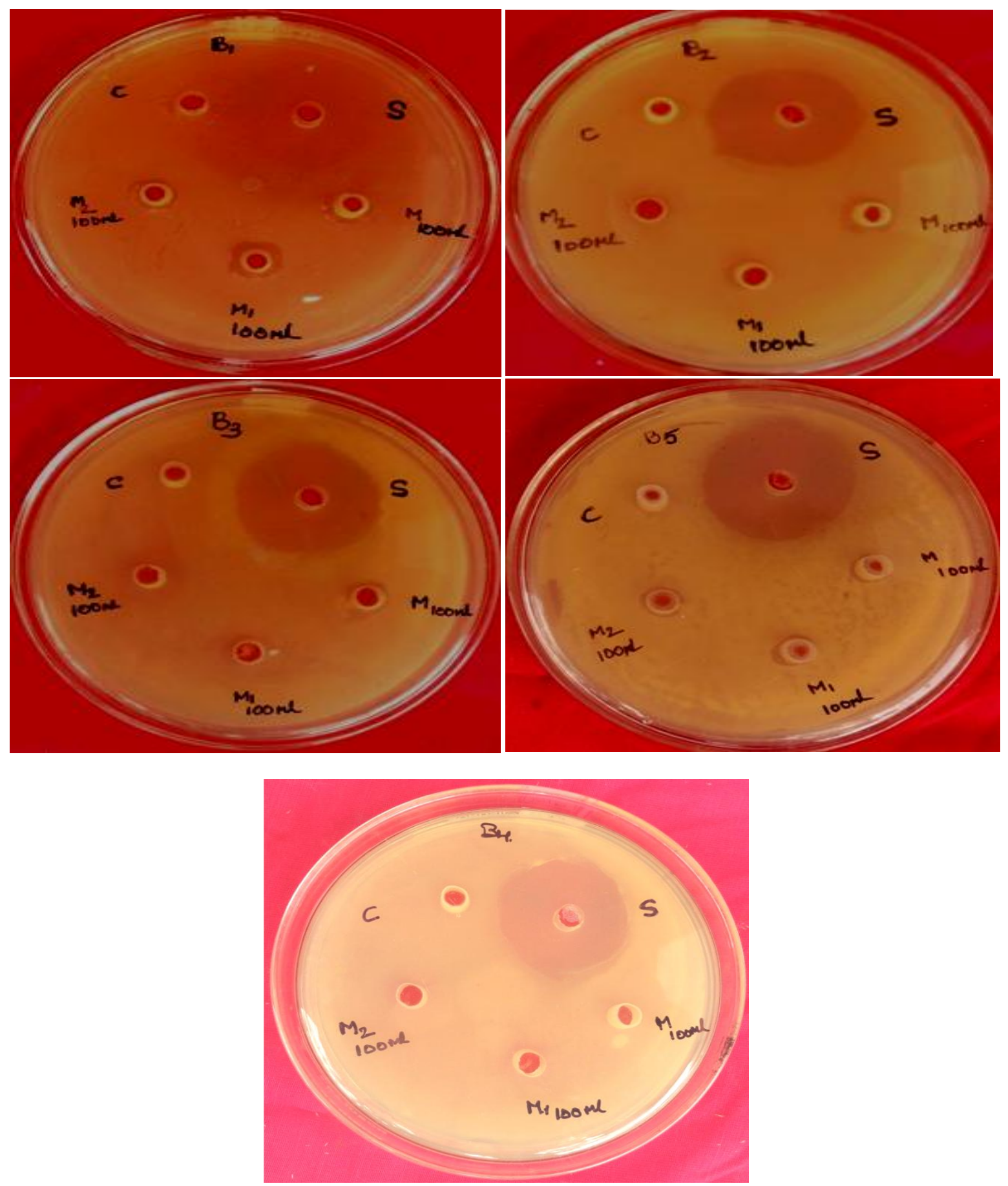

Fig 5: Representative photograph showing Antibacterial activity in Agar well diffusion method 


\section{CONCLUSIONS}

The Copolymer (NVP -MA) was synthesized. Its structure was confirmed by FTIR, $\mathrm{H}^{1-} \mathrm{NMR}$ and $\mathrm{C}^{13}-\mathrm{NMR}$. It was made to react with DEEA after hydrolysis. The anti bacterial activity of Copolymer and its macro complex was determined by agar well diffusion method. It was demonstrated that the Copolymer and its macro complex have a positive effect in controlling the growth of the Gram -ve bacteria. Gram +ve Bacteria were found to be active in the presence of these compounds. This fact can be explained by the different responsive behavior of surface layer structures of these two bacteria. The activity of M2 is more when compared to $\mathrm{M}$ and M1. This may be due to the combination of the functional groups within the single molecule. This new polymeric biocide system can be recommended for the biomedical and food industry application.

\section{REFERENCES}

[1] M. V Patel,., M. B. Dolia,., Patel, J. N., Patel, R. M., Synthesis and characterization of novel acrylic copolymers: Determination of monomer reactivity ratios and biological activity, Reactive and Functional Polymers, 2005, 65 (3), Pages 195-204.

[2] O. Vogl., A. C. Albertsson, Z. Janovic., New developments in speciality polymers: polymeric stabilizers, Polymer, 1985,26(9), Pages 1288-1296.

[3] O. Vogl., Macromolecular Architecture for the 21st Century, Journal of Macromolecular Science, Part A: Pure and Applied Chemistry, 1996, 33(10), pages 1571-1579.

[4] M. B Patel, D. A. Patel, A. Ray, R. M. Patel, Microbial screening of copolymers of 2,4-dichlorophenyl methacrylate with $N$-vinylpyrrolidone: synthesis and characterization, Polymer International, 2003,52(3) pages 367-372.

[5] E.-R. Kenawy, Biologically active polymers. IV. Synthesis and antimicrobial activity of polymers containing 8-hydroxyquinoline moiety, Journal of Applied Polymer Science, , 2001, 82(6), pages 13641374.

[6] A. Kanazawa, T. Ikeda, T. Endo, Polymeric phosphonium salts as a novel class of cationic biocides. III. Immobilization of phosphonium salts by surface photografting and antibacterial activity of the surfacetreated polymer films, Journal of Polymer Science Part A: Polymer Chemistry, 1993,31(6), pages 1467-1472.

[7] E.-S. Park, H.-J.Lee, H.Y. Park. M.-N. Kim, K.-H. Chung, J.-S. Yoon, Antifungal effect of carbendazim supported on poly(ethylene-co-vinyl alcohol) and epoxy resin, Journal of Applied Polymer Science,2001, 80(5), pages 728-736

[8] Y. Sun, G.Sun, Novel regenerable N-halamine polymeric biocides. II. Grafting hydantoin-containing monomers onto cotton cellulose, Journal of Applied Polymer Science, 2001, 81(3), pages 617-624.
[9] E.-S.Park, M.-N. Kim, J-S Yoon, Grafting of polycaprolactone onto poly(ethylene-co-vinyl alcohol) and application to polyethylene-based bioerodable blends, Journal of Polymer Science Part B: Polymer Physics, 2002, 40(22), pages 2561-2569.

[10] E.-S. Park, H. K.Kim, J. H.Shim, J.-S. Yoon, Synthesis and properties of polymeric biocides based on poly(ethylene-co-vinyl alcohol), Journal of Applied Polymer Science, 2004,93(2), pages 765-770.

[11] S. T.Oh, C. S. Ha, W. J. Cho, Synthesis and biocidal activities of polymer. III. Bactericical activity of homopolymer of AcDP and copolymer of acdp with St, Journal of Applied Polymer Science, 1994,54 (7), pages 859-866.

[12] E.-R. Kenawy, Y. A.-G. Mahmoud, Biologically Active Polymers, Macromolecular Bioscience, 2003,3(2), pages $107-116$.

[13] B. Gottenbos, H. C van der Mei, F. Klatter, P. Nieuwenhuis, H. J. Busscher, . In vitro and in vivo antimicrobial activity of covalently coupled quaternary ammonium silane coatings on silicone rubber, Biomaterials, 2002, 23(6), Pages 1417-1423.

[14] Ayhan Temiz, Sine Özmen Toğay, Ayla Şener, Güldem Güven, Zakir M. O. Rzaev and Erhan Piskin, Antimicrobial poly(N-vinyl-2-pyrrolidone-alt-maleic anhydride)/poly(ethylene imine) macrocomplexes, 2006,102(6), pages 5841-5847.

[15] Vijaysekaran, S.; Chirila, T.V.; Hong, Y.; Tahija, S.G.; Dalton, P.D.; Constable, I.J.; McAllister. Poly(Ivinyl-2-pyrrolidinone) hydrogels as vitreous substitutes: Histopathological evaluation in the animal eye, Journal of Biomaterials Science, 1996,7(8), 685696.

[16] Ranucci, H.; Spagnoli, G.; Sartore, L.; Bignottie F.; Ferruti, P. Synthesis and molecular weight characterization of end-functionalized $N$-vinyl-2pyrrolidone oligomers, Macromolecular Chemistry and Physics, 1995,196(3), 763-774.

[17] Lee, H. Y.; Yu, S.A.; Jeong K.H.; Kim, Y. Poly(vinyl pyrrolidone) conjugated lipid system for the hydrophobic drug delivery, Macromolecular Research, 2007,15(6), 547-552.

[18] Otagiri, M.; Imai, T.; Koinuma, H.; Matsumoro, U. Spectroscopic study of the interaction of coumarin anticoagulant drugs with polyvinylpyrrolidone, Journal of Pharmaceutical and_Biomedical Analysis, 1989, 7(8), 929-935.

[19] Mumper, R.J.; .Dugauid, J.G.; Anwer, K.; Barron, M.K.; Nitta, H.; Rolland, A.P. Polyvinyl Derivatives as Novel Interactive Polymers for Controlled Gene Delivery to Muscle, Pharmaceutical Research, 1996, 13(5), 701-709.

[20] Reddy, B.S.S.; Arshady R.; George, M. Copolymerization of $N$-vinyl-2-pyrrolidone with 2,4,5trichlorophenyl acrylate and with 2-hydroxyethyl 
methacrylate: Reactivity ratios and molecular weights, European Polymer Journal, 1985,21(6), 511-515.

[21] Morariu, S.; Hulubei, C. Radical Copolymerization of Functional N-Substituted Maleimides with N-Vinyl-2Pyrrolidone, High Performance Polymers, 2006, 18, 185-198.

[22] Bauduin, G, ; Boutevin, B.; Belbachir, M.; Meghabar, R. Determination of Reactivity Ratios in Radical Copolymerization: A Comparison of Methods for a Methacrylate/N-Vinylpyrrolidone System, Macromolecules,1995,28(6), 1750-1753.

[23] H.F Mark, , N.M. Bikales. C.G.Overberger and G.Menges, Encyclopedia of Polymer Science and Engineering, Wiley Interscience, New York. 1986.

[24] Kirsh, Yu. K. Water soluble Poly-N-Vinylamides. Synthesis and Physiochemical Properties. Wiley: Chichester, 1998, p 233.

[25] M. B. Huglin, K. S. Khairou, Copolymerisations of $N$ vinyl pyrrolidone with styrene and $n$-butyl acrylate, European Polymer Journal, 1988,24(3), Pages 239243.

[26] A. S Brar, R. Kumar. Microstructure analysis of $N$ vinyl-2-pyrrolidone/vinyl acetate copolymers by NMR spectroscopy, Polymer International, 2002,51(6), pages 519-529.

[27] N. Gatica, L. Gargallo, D. Radić, 2-Vinylpyridine-co$\mathrm{N}$-vinyl-2-pyrrolidone and 4-vinylpyridine-co- $\mathrm{N}$-vinyl2-pyrrolidone copolymers: synthesis and reactivity ratios, Polymer International, 1998,45(3), pages 285290.

[28] F. Abbaszadeh, O. Moradi, M. Norouzi, O. Sabzevari, Improvement single-wall carbon nanotubes (SWCNTs) based on functionalizing with monomers 2hydroxyethylmethacryate (HEMA) and $\mathrm{N}$ vinylpyrrolidone (NVP) for pharmaceutical applications as cancer therapy, Journal of Industrial and Engineering Chemistry, 2013,Available online 13 November 2013.

[29] M. Tijink, J. Janssen, M. Timmer, J. Austen, Y. Aldenhoff, J. Kooman, L. Koole, J. Damoiseaux, R. van Oerle, Y. Henskens and D. Stamatialis Development of novel membranes for blood purification therapies based on copolymers of $\mathrm{N}$ vinylpyrrolidone and $n$-butylmethacrylate, J. Mater. Chem. $B$, 2013,1, pp-6066-6077

[30] Kiselev OI, Kozeletskaia KN, Melenevskaia EIu, Vinogradova LV, Kever EE, Klenin SI, Zgonnik VN, Dumpis MA, Piotrovskiı̌ LB., .[Antiviral activity of fullerene (60)C complexed with poly $(\mathrm{N}$ vinylpyrrolidone)].[Article Russian]PMID:9777303[PubMed - indexed for MEDLINE]

[31] Butler, G.B. Cyclocopolymerisation and Cyclocopolymerisation: Marcel Dekker: Newyork,1992: p 498.
[32] Rzaev,Z. M.O. Polymers and Copolymers of Maleic Anhydride: Elm: Baku 1984: p 131 (Russain)

[33] Cowie,J.M.G. Alternating Copolymers: Plenum: Newyork, 1985; P 16.

[34] D. S. Breslow, Biologically Active Synthetic Polymers, Pure Appl. Chem.,1976,46(2-4), 103-113.

[35] H. Maeda. SMANCS and polymer-conjugated macromolecular drugs: advantages in cancer chemotherapy, Advanced Drug Delivery Reviews, 1991, 6(2), Pages 181-202.

[36] T. Hirano, T.Todoroki, R. Morita, S. Kato, Y. Ito, K.H. Kim, P. G. Shukla, H. Maeda, S. Ohashi, Antiinflammatory effect of the conjugate of superoxide dismutase with the copolymer of divinyl ether and maleic anhydride against rat re-expansion pulmonary edema, Journal of Controlled Release, 1997, 48(2-3), Pages 131-139.

[37] T. Hirano, S. Ohashi, S. Morimoto, K. Tsuda, Synthesis of antitumor-active conjugates of adriamycin or daunomycin with the copolymer of divinyl ether and maleic anhydride, Die Makromolekulare Chemie, 1986, 187(12), pages 2815-2824.

[38] Plate, N. A.; Vasilyev, A.E. Physiologically Active Polymers; Chemistry: Moscow, 1986; p 110 (Russian).

[39] J. Pató, M. Azori, F. Tüdös, Polymeric prodrugs, 1. Synthesis by Direct Coupling of Drugs, Die Makromolekulare Chemie, Rapid Communications, 1982, 3(9), pages 643-647.

[40] I. B. Iliev, M. P. Georgieva, V. S. Kabaivanov, D. V. Popov, Possibilities of obtaining polymers with supposed antitumor activity, Journal of Polymer Science: Polymer Symposia, 1979,66(1), pages 1-8.

[41] Patel, H., Raval, D.A., Madamwar, D., Sinha, T.J.M. Polymeric prodrugs. Synthesis, release study and antim-icrobial properties of polymer-bound acriflavine. Angew Makromol Chem, 1997, 245(1), 1.

[42] L. Veron, M.-C. D. Bignicourt, T. Delair, C. Pichot, B. Mandrand, Syntheses of poly[N-(2,2 dimethoxyethyl)$N$-methyl acrylamide] for the immobilization of oligonucleotides, Journal of Applied Polymer Science, 1996, 60(2), pages 235-244.

[43] C. Ladaviere, T. Delair, A. Domard, C. Pichot, B. Mandrand, Covalent immobilization of biological molecules to maleic anhydride and methyl vinyl ether copolymers - A physico-chemical approach, Journal of Applied Polymer Science, 1999,71(6), pages 927-936.

[44] V. Köseli, Z. M. O. Rzaev, E. Pişkin, Bioengineering functional copolymers. III. Synthesis of biocompatible poly $[(N$-isopropylacrylamide-co-maleic anhydride)- $g$ poly(ethylene oxide)]/poly(ethylene imine) macrocomplexes and their thermostabilization effect on the activity of the enzyme penicillin $G$ acylase, Journal of Polymer Science Part A: Polymer Chemistry, 2003, 41(11), pages 1580-1593. 
[45] Perez C, Paul M, Bazerque P, An antibiotic assay by the agar well diffusion method. Actabiologiaeet Medicine Experimentalis 1990,15,pp113-115.

\section{BIOGRAPHIES}

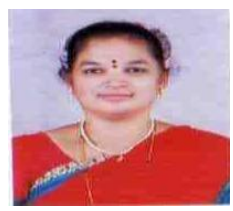

Hemalatha P, Obtained her PG degree in 1997 securing IV rank and a gold medal in Physical Chemistry at Bangalore University. Served as lecturer in First Grade College and PU Colleges at Bangalore and Tumkur. At present working as lecturer at SSIT and pursuing Ph.D. in VTU, Belgaum, Karnataka, India.

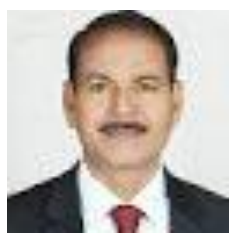

Dr. M K Veeraiah, $\mathrm{He}$ was awarded Doctorate in 1998 from the University of Mysore. Two of his students are awarded. $\mathrm{He}$ is guiding three research scholars. His areas of interests are Chemical kinetics, Polymers and corrosion studies. He has a credit to his fame in publishing 20 papers both in International and National journals. He has 39 years of experience in teaching and 22 years of experience in research and development.

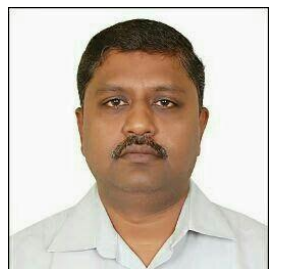

DR. S Prasanna Kumar, He has been conferred Doctoral in 2005 from Kuvempu University. He has 15 years of Experience in Polymer Synthesis, Coatings \& Adhesives. He has rendered many number of projects and headed the $\mathrm{R}$ \& $\mathrm{D}$ sections in leading polymer companies. He has published 16 papers in national and international journals.

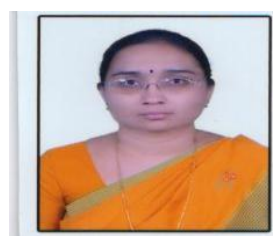

Anasuya K V, Obtained her PG Degree from Bangalore University in 1997 with II rank and two gold medals for securing highest marks in special subject Inorganic Chemistry. She has 5 years of experience and 15 years experience of teaching chemistry in PU and degree colleges. Presently she is pursuing her Ph.D. in VTU, Belgaum, Karnataka, India. 